that in future the designation "Mount Wilson Observatory" will be employed, as it is in Prof. Hale's report for 1918 .

Sun-SPOTS as Electric Vortices.-Adopting the hypothesis that sun-spots are vortices in which electrified particles produced by ionisation in the solar atmosphere are whirled at high velocity and thereby give rise to magnetic fields, Prof. Hale has built up a research in which he determines the polarity of the field or direction of rotation of the vortex by observation of the Zeeman effect in the spectrum of the spot. In the early stages of this research, before the minimum of 1912 , it was found that in the case of groups which consist mainly of two large spots these components were of opposite polarity, and that, in general, the polarities of the leading spots, and consequently of the following spots, were of opposite sign in the northern and southern hemispheres of the sun. After the minimum the surprising fact emerged that the polarities were reversed in both hemispheresthat is to say, the preceding spots of northern bi-polar groups which before the minimum were of the same polarity as the north magnetic pole of the earth were of the opposite polarity after the minimum. This state of things endured, and the interesting question arose whether a similar reversal would occur at or near the sun-spot maximum, but in Prof. Hale's report for 1918 it is stated that no general change of polarity has been observed since the maximum, which occurred in the latter half of rgiz.

\section{SCIENCE AND WAR.}

$\mathrm{O}^{\mathrm{N}}$ Thursday, June 5 , in the Senate House of the University of Cambridge, before a distinguished audience, Lord Moulton delivered the Rede lecture on science and war. After pointing out generally how the advances in scientific knowledge had revolutionised the methods of warfare since the last great European conflict' in $1870^{-}-71$, the lecturer dealt specifically with some of the more conspicuous examples of what had been achieved during the present war through the application of science to military problems. Beginning with explosives, he recalled the discovery some seventy years ago of guncotton and nitroglycerine, and showed how it led to the production of the smokeless powders that have revolutionised tactics both by land and sea. At first it was found impossible to use guncotton and nitroglycerine for anything but blasting or like destructive purposes until the discovery was made that, by the aid of certain volatile solvents, the tivo substances could be incorporated so as to produce a material : resembling gelatine, which could be formed into pieces of any shape or size. While these gelatinised powders burn with extreme rapidity, they are poor conductors of heat. Thus when the charge is fired all the pieces begin to burn on the surface, and the combustion spreads itself through each piece of the material more rapidly than the high temperature can pass inwards by conduction of heat. Hence the pieces always burn from the outside, and by making the amount of the surface large or small compared with the bulk the rate of burning of the powder can be controlled.

Besides providing a perfect propellant, science had also given the high explosives needed for shells. These are distinguished by the high rate of rise of the pressure which they produce on explosion. The rate at which the pressure comes on in a 6 -in. gun is about 10,000 tons per square inch per second, so that it rises to the full pressure of $I_{5}$ to 20 tons in something under the five-hundredth part of a second. In a good high explosive the rate of rise per second was several millions of tons per square inch, and the period

$$
\text { No. } 2589 \text {, VOL. IO3] }
$$

was a fraction of a thousandth part of a second. Hence the shattering effect of these high explosives. High explosives show the remarkable peculiarity that there are two distinct ways in which they can explode. One gives rise to a comparatively mild explosion which opens out the shell, but does little more; the other is a fierce detonation by which the shell is rent to pieces. The cause of this is not understood but it is undoubtedly connected with the intensity of the initial disturbance which sets the explosive off. By the commencement of the present war we had learnt how to detonate with fair, but not absolute, certainty the high explosives then used in the Service. But the prospect of the supply of toluene failing to equal the enormous demands of our shells necessitated a change of high explosive, and the one that was taken required special study before detonation could be ensured. It was achieved through the unremitting labours of those scientific workers who, little known to the public, have had to face and solve the innumerable problems that have presented themselves during the war. Through their labours we arrived at a degree of excellence which reduced the proportion of shells which failed to detonate from all causes to so small a figure that it was, the lecturer believed, little more than one-fifth of that of our adversaries.

Lord Moulton then referred to the changes in artillery which the new explosives had brought about, mentioning our howitzers, which, at ranges such as eight to fifteen miles, could be relied on to fire shot after shot with a variation of a few yards only, and also making some interesting statements with regard to the longrange gun which the Germans used to bombard Paris. Amongst other things, he pointed out that the distance passed over by the projectile was so great that if the Germans had taken the trouble to aim at any particular building they must have allowed nearly half a mile for the fact that during the flight the rotation of the earth would to that extent carry the target further towards the east than it would carry the gun.

The most hateful chapter of the work of science in the war was the introduction of chemical warfare. The first gas attack was on April 22, I I $^{1}$, and it was not until the following September that we were able in any way to retaliate. But our immediate reply was one that did honour to science. Due to the splendid work of the late Col. Harrison, a system of defence by gas-masks was established, in which we were for the greater part of the war far ahead of our adversaries, who succeeded in coming up to us only by learning and copying our methods.

Finally, the lecturer paid an eloquent tribute to the assistance rendered by science in the war in dealing with disease and wounds, with particular reference to the success which had attended the use of anti-tetanus serum, to the reduction of the rate of mortality in spotted fever to one-tenth of its former value, and to the complete elucidation of the mode of transmission of bilharziasis, a disease with which we were faced through the presence of large contingents of our troops in Lower Egypt. Lord Moulton's conclusion was that one overmastering lesson was to be derived from the contemplation of all that science had done in the war. She had made mankind too formidable a being to be permitted to have recourse to it. The uncontrolled indulgence on the part either of a nation or of an individual in the exercise of the power that science had placed within reach was too directly fatal to civilisation itself. It was easy to criticise the League of Nations and to point out the difficulties, and even impossibilities, with which it was faced, but we should never forget that some combined action of that type was an imperative necessity. 